\title{
3B Baskı Teknolojisi Kullanılarak Hızlı Prototipleme Yapımı ve Nesnelerin Üretimi
}

\author{
${ }^{1}$ Abdurrahman AYDIN* ${ }^{2}$ Fatih KAHRAMAN \\ ${ }^{1}$ Faculty of Engineering, Department of Mechanical Engineering Dokuz Eylül University, Turkey \\ ${ }^{2}$ Faculty of Engineering, Department of Mechanical Engineering Dokuz Eylül University, Turkey
}

\begin{abstract}
Özet:
Hızlı prototipleme teknolojileriyle çeşitli malzemeler kullanarak dijital ortamdaki üç boyutlu modeller kalıp veya fikstüre gerek kalmaksızın somut nesneler halinde üretilebilmektedir. 3B yazıcılar zaman ve maliyet tasarrufu, geometrik özgürlük, çevreye zarar vermeme, güvenlik ve gizlilik gibi avantajları nedeniyle farklı alanlarda uygulamaları yapılmaktadır. Üç boyutlu yazıcılar günümüzde birçok alanda kullanılan ve hızla gelişen bir teknolojidir. 3B yazıcı teknolojisi geliştikçe ve kullanımı yaygınlaştıkça yeni kullanım alanları ortaya çıkmaktadır. 3B yazıcılar plastik, silikon, cam ve diğer bazı malzemeleri yazdırabilmektedirler. Bu bildiri kapsamında üç boyutlu yazdırma teknolojileri tanıtılacak, pratikte nasıl kullanıldığı açıklanacak ve hangi alanlarda kullanıldığı incelenecektir.
\end{abstract}

Anahtar kelimeler: 3B, 3B yazıc1, hızlı prototip

\begin{abstract}
:
Three dimensional modals can be produced as concrete objects without a mold or fixture requirement by using various materials with rapid prototyping technologies. 3D printer is one of them and is being used in many different fields because of its cost and time saving, geometrical independency, environmental friendly, security and confidentiality advantages. Today, 3D printing is a rapidly developing technology which is used in many fields. New fields of use are emerging as 3D printer technologies develop and the use of 3D printers become widespread. 3D printers can print plastic, silicone, glass and various type of materials. In this study, 3D printing technology will be introduced and its practice will be explained and the fields of use will be examined.
\end{abstract}

Key words: 3D, 3D printer, rapid prototyping

\section{Giriş}

3 boyutlu (3B) yazıcılar bilgisayar verisini el ile tutulabilir gerçek nesnelere dönüştüren makinelerdir. 3B yazıcılar 20 yılı aşkın süredir hayatımızda olmasına rağmen, ancak günümüzde kitlelere hitap edecek konuma gelmiştir.

Üretim için geleneksel ya da yenilikçi yöntemler kullanılabilir. Fakat ortaya çıkan ürünlerin tasarım değeri yüksek, özgün ve kullanıcıların ihtiyacına cevap verebilecek optimum özelliklere

*Corresponding author: Address: Faculty of Engineering, Department of Mechanical Engineering Dokuz Ełlia University, İzmir TURKEY. E-mail address: abdurrahmanaydin@yandex.com, Phone: +902323019239 
sahip olması önemlidir [1]. Özgün tasarımlar oluşturmada etkili olan hususlar yenilikçi yöntem ve kullanılan malzemelerin sahip olduğu özellikler ve sağladığı avantajlardır [2].

Geleneksel yöntemler eksiltmeli üretim tekniğiyle (kesme, oyma ve talaş kaldırmaya dayalı) yapılırken eklemeli üretim (additive manufacturing) olarak adlandırılan 3B baskı yöntemi geleneksel üretim yönteminin tam tersi şeklinde, yani ürün katmanlar halinde birbiri üzerine eklenerek ortaya çıkmaktadır. Prototipleme ürün geliştirme sürecinde hâlihazırda en yaygın kullanılan metottur. Daha dar tolerans aralığında çalışma, daha az yüzey pürüzlülüğü ve malzeme kalitesi prototipleme açısından önemlidir [3].

Üç boyutlu parça üretimi ilk olarak Charles Hull' un foto polimeri lazer 1şını yardımıyla kürleyerek katman katman katı cisim oluşturabileceğini fark etmesiyle başlamıştır. 1980' li yılların başında uzun süren deneme ve uğraşlarından sonra bilgisayar destekli üretim kullanarak ilk 3D yazdırılmış obje olan çay kupasını üretmeyi başarmıştır. 1986 senesinde Streolithografi adını verdiği yöntemini geliştirerek patentini almıştır[4,5]. Daha sonra Scott Crump polimerleri birbiri üzerine ergiterek 3D parçalar üretilebilen yöntem olan FDM-Fused deposition Modeling (Ergitmeli model yığma) teknolojisini geliştirmiştir ve 1989 yılında patentini almıştır [4,6]. Bugün Charless Hull'un kurduğu 3D Systems ve Scott Crump'un eşi ile birlikte kurucusu olduğu Stratasys, 3D yazıcı sektörünün en büyük iki firmasıdır[4].

3B yazıcılar plastik, silikon, gıda, cam ve diğer bazı materyalleri yazdırabilirler ve bunlarla hava araçlarının bileşenleri, mücevherat, moda tasarımı, tıp ve dişçilik, otomotiv yedek parçaları ve diğer endüstrilerde üretim yapmak için kullanılabilirler.

Yakın gelecekte yedek parça sipariş etmek ve uzun bekleme sürelerine katlanmak yerine yazıcıdan çıktı almak ya da bir oyuncağı mağazadan satın almak yerine internet üzerinden 3D CAD modelini indirerek ve üzerinde değişiklikler yaparak evlerde çıktı almak büyük bir devrim olacaktır $[7,8]$.

\section{3B Yazıcılarda kullanılan malzemeler}

3D yazıcılarda sık olarak Akrilonitril Butadin Stiren (ABS) ve Polilaktik Asit (PLA) termo plastik polimer malzemeleri kullanılmaktadır.

ABS petrol ürünüdür, hafif ama sert bir termo plastiktir ve aseton ile çözülebilmektedir. Lego parçaları bu malzemelerden yapılmaktadır. ABS ile imal edilen parçalar erime başlangıç sıcaklığ 1 $105^{\circ} \mathrm{C}$ olduğundan $80^{\circ} \mathrm{C}$ üzerinde yumuşama ve şekil bozukluğu başlamasından dolayı $-20 /+80$ ${ }^{\circ} \mathrm{C}$ sıcaklık aralığında kullanılabilmektedir. ABS' nin kötü özelliklerinden birisi yüksek sıcaklığa maruz kaldığında HCN gazı çıkarmasıdır. HCN, 2. Dünya savaşında gaz odalarında kullanılan zehirli bir gazdır. Bu gibi nedenlerden dolayı 3D yazıcılarda ABS malzemesi kullanıldığı zaman ortamın havalandırılması sağlık açısından çok önemlidir[9].

Nişasta içeren ürünlerden elde edilen PLA, istatiksel olarak en çok kullanılan 3D yazıcı malzemesidir. Nişastadan üretildiği için sağlık açısından ABS' den daha iyidir ve insan vücudu 
içerisinde parçalanması 0,5 ile 2 yıl arasında gerçekleşmektedir. ABS, sağlık endüstrisinde implant ve protez imalatında kullanılmaktadır. ABS, daha düşük sıcaklıklarda erimesi ve buna bağlı olarak kolay çalışılabilen bir malzeme olması, özellikle ev kullanıcıları tarafından tercih edilme sebebidir. Daha düşük çarpılma ihtimalinden dolayı 1sıtıcı bir platforma gerek duyulmaz[9].

Alumide, seramik, gümüş, paslanmaz çelik, 3D yazıcılarda kullanılan diğer malzemelerdir [7].

\section{3B Yazıcı ile Tasarım Aşamaları}

3D yazıcı ile tasarım ve üretim döngüsü belirli aşamaları içermektedir [10]. Bu aşamalar:

a. Dataların bir tarayıcı tarafından kaydedilmesi: Scanner (tarayıcı), Sistemde verilerin toplanıldığı parçasıdır. Var olan bir parça ya da modelin 3 boyutlu tarama cihazlarıyla sayısallaştırılarak bilgisayar ortamına aktarılmasıdır[11].

i. $\quad$ Optik tarayıcı: Beyaz ışık, renkli ışık ya da lazer projeksiyonu kullanılarak güdük üzerinden optik tarama yapılabilen sistemlerdir.

ii. Mekanik tarayıcı: İğne ucu, küre ya da pin kullanarak güdük üzerinden mekanik tarama yapılan sistemdir.

b. Taranıp kaydedilen dataların üzerinde uygun ve istenilen revizyonları/restorasyonları yapılabilmesini sağlayacak sistem: Software (yazılım)

i. Çoklu nokta bulutlarını birleştirme

ii. Üçgenleştirme/Sadeleştirme

iii. Segmentasyon

iv. Yüzey örülmesi

v. Yüzey ve çizgisel kalıp oluşturma

vi. $\quad$ Pürüzsüz çoklu alanlar oluşturma

vii. Komşu grafikler oluşturma

viii. Sınırları ve bağlantıları belirginleştirme

ix. Model oluşturma ve meshleme

c. Sonuç restorasyonunu ortaya çıkaracak üretim teknolojisi: Hardware (Donanım)

Parça tasarımı yapıldıktan sonra CAD programlarının kendi uzantısından farklı olarak. STL (STrereoLithography) formatına dönüştürülür. Günümüzde kullanılan CAD programlarının (Autocad, CadKey, I-Deas, Invertor, Rhino, Solidworks, Unigraphics vs.) neredeyse tamamı bir STL dosyası üretebilmektedir. Bu format, renk, doku veya diğer ortak model nitelikleri dışında üç boyutlu bir nesnenin yalnızca yüzey geometrisini tanımlar. STL formatı 3D parçanın malzeme olan kısımlarını katmanlara ve üçgenlere ayırarak malzemeli ve malzemesiz bölgeleri ağ gibi örmektedir $[4,12]$

\section{3D Yazıcı Kullanım Alanları}

3B yazıcı teknolojisi kişiye özgü implant tasarımı ve üretimine olanak sağlamaktadır. Bu üretim sürecinde ilk olarak hastanın ağız morfolojisi ve fizyolojisine uygun olarak malzeme seçimi yapılır ve ardından bu malzemenin CAD/CAM sistemleri ve 3B yazıcı sistemleri için de 
kullanılabilir olup olmadığına bakılır. Daha sonra tarama işlemi ile bilgisayara aktarılan veriler CAD/CAM programları ile analiz edilip gerekli düzeltme ve iyileştirme işlemleri yapılarak veriler 3B yazıcıya gönderilir ve baskı işlemi gerçekleştirilir. Kara ve arkadaşları yaptıkları bir çalışmada kişiye özgü implant üretiminin yöntem ve modellemesini ele almışlar ve bu yöntemin gelişen yöntemlerle birlikte tedavi verimini önemli ölçüde arttırdığı sonucuna varmışlardır [10].

Günümüzde üçüncü dünya ülkelerine doktor göndermek pek mümkün olmamaktadır. Hastaların 3B kayıtlarının çıkarılmasıyla internet ağı üzerinden doktorlar aynı hasta üzerinde tartışıp yorumlar yapabilmekte ve uygun tedavi yöntemini belirleyebilmektedirler [11].

Adli Tıpta 3B kayıtların alınması hâkim, savcı, avukat ve diğer insanlarla doktorlar arasındaki iletişimi kolaylaştıracaktır. Otopsi sonrası ceset defnedildikten sonra elde sadece otopsi raporu ve 2 boyutlu görüntüler kalmaktadır. Otopsi raporu öznel olabileceği gibi 2 boyutlu görüntülerde farklı açıdan bakma, derinlik, renk gibi konularda yetersiz kalmaktadır. Bunun için 3B kayıt cesetlerin ölümsüzleştirilmesine olanak sağlamaktadır [11].

Bursa Aktopraklık kazılarında elde edilen 8500 yıllık kafatasına ait kemikler rekonstrükte edildikten sonra 3B teknolojisi ve Anadolu popülâsyonunun yüz doku kalınlıklarından faydalanılarak yeniden yüzlendirme işlemi yapılmıştır ve elde edilen model 2014 yılından itibaren Bursa Arkeoloji Parkında sergilenmektedir [11]. 8500 yıllık kafatasına ait kemiklerden 3B yazılımlar ile 3B tarayıcı kullanılarak yapılan fasiyal rekonstrüksiyonu Şekil 1' de gösterilmiştir.

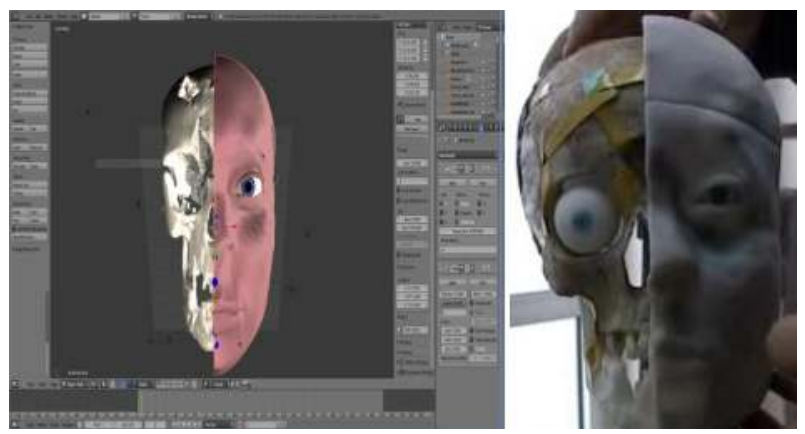

Şekil 1. 8500 yıllık kafatasına ait kemiklerden 3D yazılımlar ile 3D tarayıcı kullanılarak yapılan fasiyal rekonstrüksiyon[11]

3B yazıcılar ile plastik, metal gibi çeşitli malzemelerle üretim yapılabildiği gibi seramik üretmek üzere plastik ve toz halindeki çamur malzemelerle de üretim yapmak mümkündür. Seramik malzeme ile sadece harç yığma ile üretim değil aynı zamanda da toz bağlama ve SLS (seçici lazer sinterleme) sistemine göre de üretim yapılmaktadır. Bu sistemler el ile şekillendirilemeyecek kadar karmaşık formların şekillendirilmesinde oldukça başarılıdır. Ancak malzemenin tam olarak birbirine kaynaşmamasından kaynaklı, formun yüzeyinde boşluklar oluşabilmektedir [11]. Martinez ve Can yaptıkları bir çalışmada bilgisayar destekli seramik üretim yöntemi olarak 3B yazıcıların günümüz koşullarında uygulanmasını ele almışlar ve $3 \mathrm{~B}$ yazıcıların seramik sanatı ve bakış açılarını genişleten bir etkisi olduğu sonucuna varmışlardır [11]. 
Aldanmaz ve Sever, 3B yazıcıların gıda materyallerinin dizaynında kullanımı ile ilgili araştırmaları derledikleri çalışmalarında, 3B yazıcı teknolojisinin gıda sektöründe de büyük bir potansiyele sahip olduğunu vurgulamışlardır. Özellikle yaşlılar, çocuklar ve sporcular gibi özel tüketici kategorileri için özel taleplerini karşılayan gıdaların tasarımı yapılabilmektedir. 3B teknolojisi kişiye özel beslenme formülleri içeren gıdaların üretilmesine olanak sağlamaktadır[13]. Mürekkep püskürtme teknolojisine dayalı 3B gıda yazıcı örnekleri Şekil 2' de gösterilmiştir.
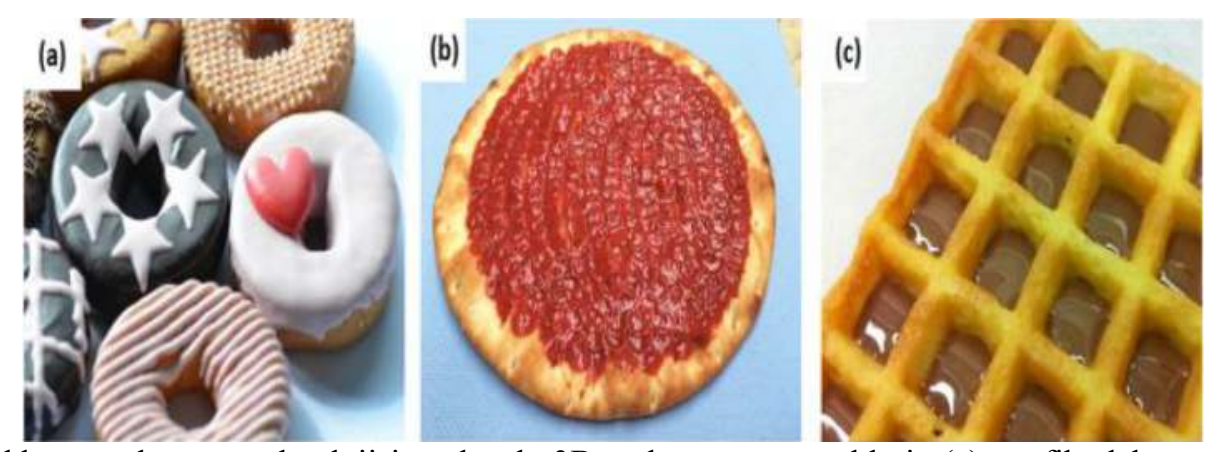

Şekil 2. Mürekkep püskürtme teknolojisine dayalı 3B gıda yazıcı örnekleri: (a) grafik dekorasyon, (b) yüzey doldurma ve (c) boşluk biriktirme [13]

Çelebi ve arkadaşları, bilgisayarlı tomografi verileri üzerinden CAD programları ile başarılı şekilde dijital modeller elde etmişler ve elde edilen bu modeller ile hasarlı olan kafatasının 3B yazıcı ile baskısı yapılarak kusurlu olan bölgeye uygun implant tasarımı ve imalatını gerçekleştirmişlerdir. Ayrıca bilgisayarlı tomografi tarama görüntülerinin çıktıları alınarak cerrahi operasyonlarda yardımcı olarak kullanılabileceği ve bu şekilde cerrahi operasyon daha kısa bir sürede yapılabileceği sonucuna varmışlardır [14]. Bilgisayarlı tomografiden alınan verilerle üretilmiş kafatasının tasarım ve üretim aşamaları Şekil 3' te gösterilmiştir.

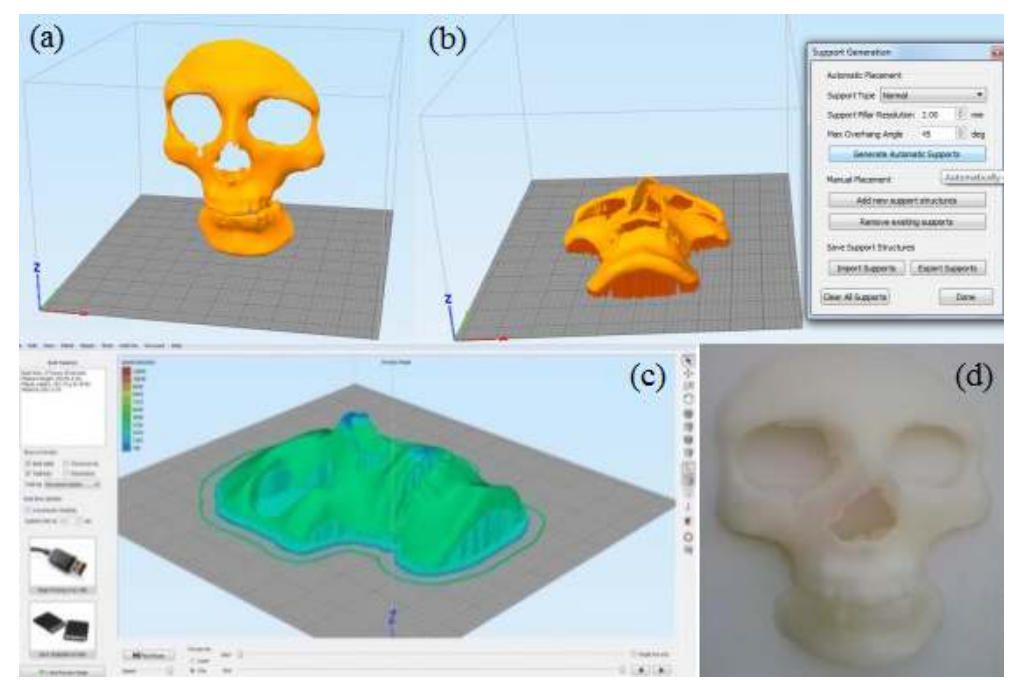

Şekil 3. Bilgisayarlı tomografiden alınan verilerle üretilmiş kafatası a) Tabla eksenine dik gelen model b) Tablaya hizalama işlemleri c) Yazdırma işlemi öncesi Simplfy3D programı üzerindeki ekran görüntüsü d) kafatasının yazıcıdan alınmış çıktısı [14] 
Düşük viskoziteli biyo mürekkeplerden, insan korneasını üretmek için hızlı ve etkili bir yöntem olarak 3B biyo baskı teknolojisi kullanılabilir. Isaacson ve arkadaşları tarafindan yapılan araştırmalar ve deneyler kornea doku mühendisliği uygulamaları için 3B biyo baskı uygulaması büyük bir umut göstergesidir [15].

Proje tabanlı ve problem çözmeye dayalı eğitim ve öğrenme etkinliklerinde, robotik uygulamalarında ve materyal üretmek için 3B yazıcılar kullanılmaktadır. 3B yazıcılar ile üretilen modeller öğrencilerin, gerçek yaşam problemlerine çözüm bulmaya çalışırken fikirlerini somut nesneler üzerinde deneme firsatı bulabilecekleri bir ortam sağlayacaktır. Ayrıca, 3B yazdırma teknolojilerinin öğrencilerin fikirlerini gerçeğe dönüştürebilmeleri ve teknik olarak donanımlı bireyler haline gelmelerinde yardımcı olma potansiyeli bulunmaktadır [16]. Coğrafya eğitiminde rölyefler, Sanat eğitimde sanatsal nesneler, Biyoloji eğitiminde molekül modelleri tasarımı ve yazdırılması gibi birçok uygulama örneği bulunan 3B yazıcı teknolojileri sayesinde, zorlu kavramların öğrencilere açıklanması, öğrencilerin ilgisini çekip daha etkin derse katılımlarının sağlanması ve sınıf içi etkileşim daha kolay olması sağlanabilmektedir [17]. Ayrıca 3B yazıcılar, mühendislik, mimarlık ve güzel sanatlar öğrencileri tarafindan prototip geliştirme uygulamalarında kullanılmaktadır. Biyoloji ve Tıp öğrencileri kemik yapıları gibi kısımları fiziki olarak hissederek öğrenmelerine olanak sağlamaktadır [9].

3B yazıcılar kullanarak, 1S1 geri kazanımlı havalandırma cihazlarında mevcut kullanılan 1s1 değiştiricilerin yerine geçebilecek, polimer esaslı bir 1sı değiştiricinin üretimi yapılabilmektedir. Isı değiştiricinin geometrik parametreleri değiştirilerek, kullanılabilecek farklı geometrik tasarımlar yapılabilmektedir [18].

Makine parçalarının 3B yazıcılar ile imalatı mümkündür. Lee ve arkadaşları yaptıkları bir çalışmada 3B baskı ile imal ettikleri bilyeli rulmanların sürtünme performansı ve uygulanabilirliği konusunda araştırmalar yapmışlardır. Çalışma sonucunda 3B baskı ile üretilmiş rulmanların sabit yük ve dönme hızı altında kullanılabileceğini belirtmişlerdir [19].

Doğası gereği inovasyon kavramı ile sürekli etkileşim halinde olan moda, kaliteli ve sürdürülebilir ürünler yaratmak için bilimi araç olarak kullanmaktadır. 3B yazıcılar birçok alanda olduğu gibi moda tasarımında da son yıllarda sıklıkla kullanılmaya başlanmış, geleceğin modasını değiştirebilecek özellikte çalışmalara imza atılmıştır [1]. 3B yazıcıların moda ve tekstil tasarımında kullanım örnekleri Şekil 4' de gösterilmiştir. 3B yazıcıların kullanımı iki amaçla yapılmaktadır: birincisi giysinin bütün olarak vücudun taranmasıyla kişiye özel üretilebilmesidir, ikincisi tekstil yüzeyinde temel teşkil eden dokuma ya da örme ile oluşturulmuş yüzeylere alternatif olabilecek farklı bağlantı şekilleriyle bilinen dokuma ve örme kumaşlara alternatif yüzeyler elde edilebilmesidir. Moda giyim endüstrisinde de diğer endüstri alanlarında olduğu gibi tasarımın bilgisayar ortamında yapıldığı ve üretimin de bir komutla başlatıldığı insansız üretim süreçleri hedeflenmektedir, 3B yazıcılar böyle bir üretim sistemi için zemin oluşturabilir [21]. 


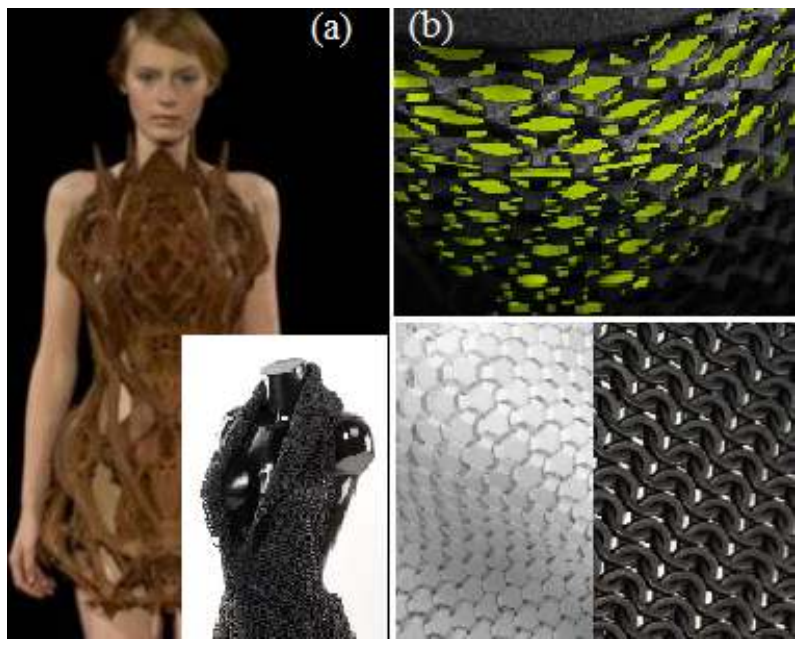

Şekil 4. Moda ve giyim tasarımında 3B yazıcıların kullanımı a) giysinin bütün olarak üretilmesi b) dokuma/örme yüzeyleri [21]

Mimarlar ve kent tasarımcıları topografik modellere ihtiyaç duyduklarında araziyi doğru bir şekilde analiz etmek amacıyla hızlı ve hassas bir çözüm olan 3B yazıcı çıktılarından faydalanırlar. 3B baskı işlemi prototip yapı çalışmalarında, mimari sunum modelleme çalışmalarında, mimari modelleme çalışmalarında oldukça işe yarayacak bir uygulamadır. Ayrıca topografik verilerle tamamlanmış ve minyatürize edilmiş şehir manzaralarının basılması için de kullanılması Şekil 5' de gösterilmiştir [22].
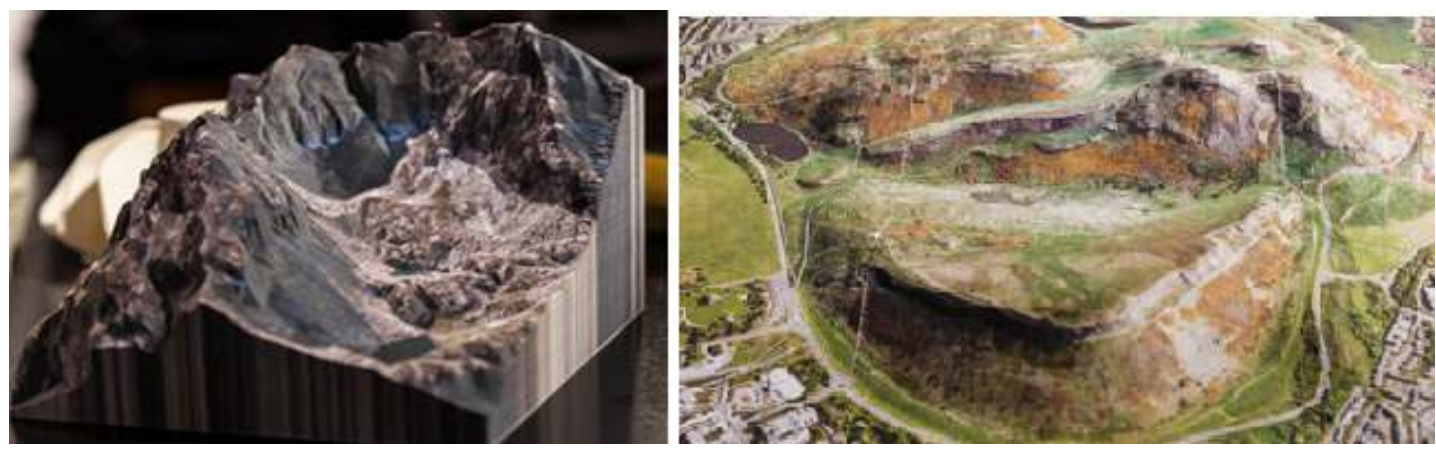

Şekil 5. 3B teknolojisinin arazi modellemesinde kullanılması [22]

\subsection{B Yazıcıların Sağladığı Avantajlar ve Dezavantajlar}

3B yazıcıların toptan üretime oranla önemli bir üstünlüğü talebe uygun, kişiye özel, sınırsız çeşitlilikte ürün üretme imkânı sağlamasıdır [3].

3 boyutlu (3D) modelleme teknolojisi, fikirlerin uygulanması ve denenmesi için gerekli olan parça ve ürün ihtiyaçlarını hızlı, ucuz ve kaliteli bir şekilde çözüm getirmektedir [4].

3B yazıcıların kullanılmasıyla geleneksel yöntemlerle üretimde ihtiyaç duyulan makine, teçhizat ve işçilik minimize edilir. Frezeleme, tornalama gibi talaşlı işleme üretim yöntemlerine 
gereksinim duymadığı için ciddi işçilik gerektiren işlemleri ortadan kaldırır. İşçilik azaldığı için zamandan kazanç sağlanır [9].

Karmaşık geometrilere sahip parçalar, bilgisayar ortamında tasarlandıktan sonra rahatlıkla gerçek nesnelere dönüştürülebilirler [9].

Kullanılan sarf malzemesi (filament) genellikle mısır nişastasından üretilmiş bioplast olan PLA' dır. $\mathrm{Bu}$ malzemenin sağlığı olumsuz yönde etkileyen tespit edilmiş ve ispatlanmış bir zararı yoktur. PLA ergitilirken çevreye zarar veren gaz çıkarmaz ve koku yapmaz. Bunlara ilave olarak doğada çözünebilme özelliği vardır [9].

Tarama işlemi yapılarak, geleneksel ölçü alma yöntemleri ortadan kaldırıldı̆̆ı için verilerin bilgisayar ortamına atma süresi ve dolayısıyla işlem için gerekli olan bekleme süreleri kısa olacak ve modellerin daha kısa sürede elde edilmeleri sağlanacaktır [10].

3B yazıcı teknolojisinin pek çok sektöre olumlu yansımaları olacağı beklense de zarar verebileceği alanların olacağı tahmin edilmektedir. Bir silahın tüm parçaları 3B yazıcı ile kısa sürede üretimi gerçekleştirilebilir, havalimanları ve tren garları gibi kalabalık kitlelerin bulunduğu ortamlardaki güvenlik noktalarından fark edilmeden geçebilir. $\mathrm{Bu}$ da gelecekte 3B yazıcıların çok ciddi güvenlik açıklarına neden olabileceğini göstermektedir[3].

\section{Sonuçlar ve Öneriler}

$\mathrm{Bu}$ çalışmada 3B yazıcılarla ilgili olarak mevcut sistemler, patentler ve literatür araştırması yapılmıştır. Malzeme bilimi ve 3D yazıcılarda gelişen teknolojiye paralel olarak, yakın gelecekte günlük hayatta kullandığımız basit ürünlerin evlerde üretilebileceği sonucu çıkarılmıştır.

3B yazıcılar mucitlerin, mühendislerin, endüstriyel tasarımcıların prototip yapmasını kolaylaştıracağı için yeni ürün geliştirme sürecini hızlandıracağı aşikardır.

Mimarlar ve şehir planlamacıları 3B yazıcılarından çıktı alarak mimari sunum, mimari modelleme ve topografik modelleme çalışmalarında kullanmaları oldukça yararlı olacaktır.

Hasta ile birebir uyumlu implant ve protezlerin imalatında 3B yazıcıların kullanılmasıyla hastaya hem estetik hem de fonksiyonellik açısından fayda sağlayacağı için ve hasta ile implant ve protez uyum oranının yükselmesiyle hastaların sağlık hizmetindeki memnuniyet oranını artıracaktır.

3B yazıcıların olumsuz ve zararlı ürün üretiminde kullanılmasının önüne geçmek için gerekli yasal düzenlemelerin yapılması ve üretimin kontrol altında tutulması gerekmektedir.

3B yazıcıdan daha hızlı ve kaliteli baskı alınması, mukavemetli parçaların üretilmesi, üretim toleranslarının daraltılması, tasarım optimizasyonunun yapılması bu teknolojiyle ilgili yapılabilecek çalışmalara öneri olarak sunulabilir. 


\section{Kaynaklar}

[1] Nadasbaş, SE, Çileroğlu, B. (2018). Moda Tasarımında 3 Boyutlu Yazıcıların Malzemeişlevform Odaklı Kullanımları Ve Çok İşlevli Modüler Giysi Tasarımı Çalışması, Jass Studies- The Journal of Academic Social Science Studies, Doi number: http://dx.doi.org/10.9761/JASSS7452, Number: 66 Spring II 2018, p. 231-257.

[2] Zaimoğlu Ö, Yıldıran M. Moda tasarımında inovatif bir yöntem: üç boyutlu yazıcılar ile giysi tasarımı ve uygulamaları. İdil dergisi, Cilt 6, Sayı 38, Volume 6, Issue 38, DOI: 10.7816/idil-06-38-21, 2017

[3] Çalışkan MG. Üç boyutlu yazıcılar ve gelecekte yaratacağı olası fikri haklar çatışmaları. FMR Dergisi, 2015/2, s 59-90

[4] Oktay K. Ergitmeli yığma yöntemiyleüretim yapan 3D yazıcılarda çift filament süren ekstruder tasarımı. İstanbul Teknik Üniversitesi Yüksek Lisasns Tezi, 2015, İstanbul

[5] http://www.ntboxmag.com/2017/05/08/3d-yazicinin-mucidi-chuck-hull/, erişim tarihi 26.08.2018

[6] http://investors.stratasys.com/news-releases/news-release-details/inventor-fdm-3dprinting-and-co-founder-stratasys-scott-crump erişim tarihi 26.08.2018

[7] Çallı L, Taşkın K. 3D Yazıcı Endüstrisinin Oluşturacağı Yeni Pazarlar ve Pazarlama Uygulamaları. ICEB 2015, Uluslararası Vizyon Üniversitesi, Gostivar, Makedonya

[8] Stefano TF. 3D Printing: A New Dimension for Manufacturing. www.ecommercetimes.com: http://www.ecommercetimes.com/story/75695.html

[9] Polat E. 3D printer (Üç boyutlu yazıcı). Karabük Üniversitesi Lisans Bitirme Tezi, Karabük, 2016

[10] Kara E, Buldum BB, Yılmaz Ç, Özkaya N. 3B yazıcı ile kişiye özel implant tasarımı, 3B baskı teknolojileri uluslar arası sempozyumu (International symposium on 3D printing technologies), 218-226

[11] Martinez HV, Can E. Bilgisayar destekli seramik üretim yöntemi olarak üç boyutlu yazıcılar ve günümüz koşullarında uygulama örneği, Anadolu Üniversitesi Sanat ve Tasarım dergisi, 2015, Eskişehir

[12] https://all3dp.com/what-is-stl-file-format-extension-3d-printing/\#pointone, erişim tarihi 26.08.2018

[13] Aldanmaz EA, Sever R. Gidaların Dizaynında 3 Boyutlu Yazıcı Teknolojisi Uygulamaları. 19. Akademik bilişim konferansı, 2017, Aksaray

[14] Çelebi A, Tosun H, Önçağ A Ç. Hasarlı bir kafatasının üç boyutlu yazıcı ile imalatı ve implant tasarımı. International Journal Of 3D Printing Technologies and Digital Industry, $1: 1(2017) 27-35$

[15] Isaacson A, Swioklo S, Connon CJ. 3D bioprinting of corneal stroma equivalent. Experimental Eye Research 173 (2018) 188-193

[16] Kuzu Demir EB, Çaka C, Tuğtekin U, Demir K, İslamoğlu K, Kuzu A. Üç Boyutlu Yazdırma Teknolojilerinin Eğitim Alanında Kullanımı: Türkiye'deki Uygulamalar. Ege Eğitim Dergisi 2016(17) 2: 481 - 503, 2016

[17] Kökhan S, Özcan U. 3D yazıcıların eğitimde kullanımı. Bilim, Eğitim, Sanat ve Teknoloji Dergisi (BEST Dergi), Cilt 2, Say1 1, Sayfa 81-85, 2018

[18] Ayar O, Yalçınkaya MA, Karadeniz ZH, Gezgin E, Toksoy M. Isı geri kazanımlı havalandırma cihazları için 3 boyutlu yazıcı ile üretilebilecek ısı değiştirici tasarımı ve 
imalat1. 13. Ulusal Tesisat Mühendisliği Kongresi (TESKON 2017), Sayfa 1575-1588, 2017, İzmir

[19] Lee YJ, Lee KE, Lee CH. Friction performanca of 3D printed ball bearing: feasibility study. Results in Physics 10 (2018) 721-726

[20] Yıldıran M. Moda giyim sektöründe üç boyutlu yazıcılarla tasarım ve üretim. Süleyman Demirel Üniversitesi Güzel Sanatlar Fakültesi Hakemli Dergisi ART-E Mayıs-Haziran'16 Say1:17, 2016

[21] http://www.yeniisfikirleri.net/a4-kagidi-kullanan-3-boyutlu-yazici/ erişim tarihi 26.08.2018 